\title{
Novel cell therapy for type 1 diabetes mellitus
}

\author{
Friedrich C. Luft
}

Published online: 9 May 2009

(C) Springer-Verlag 2009

Pancreas transplants are an established therapy for type 1 diabetes mellitus (T1DM). However, they are beset with various clinical problems and cannot solve the increasing burden accrued by T1DM patients [1]. Transplantation of pancreatic islet cells into the portal vein can virtually normalize blood glucose levels, while circumventing a number of problems associated with pancreas transplantation [1]. However, this approach, including the problems associated with cadaveric organ and cell harvesting, makes these options practicable for only a few T1DM patients. Generating surrogate insulin-producing cells is feasible and rodent studies suggest that such cells may be adequate to treat T1DM [2]. However, such cells do not have the sophisticated machinery to detect glucose levels that is possessed by native islet cells. Thus, their ability to steer insulin release in response to glucose levels is not given.

The report by Unniappan and colleagues in this issue presents another option [3]. They considered the possibility of using a drug-operated system that could induce target cells to release insulin each and every time the drug stimulus is given. The drug inducing the "gene-switch" and subsequent insulin production in the cells is mifepristone. Mifepristone is notorious in other circles as a progesterone antagonist that can function as an abortifacient in the first trimester; however, the drug also has numerous other possible clinical applications. A C-terminal deletion mutant of the human progesterone receptor fails to bind to progesterone but can bind mifepristone. This mutant receptor construct can activate transcription of reporter

F. C. Luft $(\bowtie)$

Experimental and Clinical Research Center, Max Delbrück Center

for Molecular Medicine, Helios Klinikum-Berlin,

Berlin, Germany

e-mail: luft@charite.de genes containing the progesterone response element when mifepristone is present. Wang et al. [4,5] developed this gene-switch system based on this technology that permits a regulatory system applicable for gene-transfer studies (Fig. 1). A regulator is constructed. The transactivator gene encodes a chimeric regulator (GLVP) that consists of a VP16 activation domain, a Gal4 DNA binding domain, and a truncated progesterone binding domain that responds to mifepristone. Any promoter can be used to target the expression of the regulator to any particular cell or tissue of interest. Next, a target must be constructed. The target can be any gene with an SV40 polyadenylation signal placed under the control of a minimal promoter. Upon activation, the regulator then binds to the Gal4 sites and induces target gene expression. The regulator is inactive without mifepristone. When mifepristone is added, the activated regulator dimerizes and binds to the Gal4 DNA binding site that induces the target gene expression. Unniappan et al. used exactly this drug-dependent regulatory system [3].

The next tool the investigators needed was a suitable cell line. They reasoned that the gut might be a source of potentially therapeutic cells. For their purpose, they selected gut $\mathrm{K}$ cells that have been shown to express glucokinase, the glucose sensor of pancreatic beta cells. Transgenic mice expressing human insulin under the control of a $\mathrm{K}$ cell-specific promoter were shown to be resistant to T1DM development induced by the beta cell toxin streptozotocin in an earlier study [6]. $\mathrm{K}$ cells release glucose-dependent insulinotropic polypeptide (GIP), a gastrointestinal hormone that is secreted in response to food intake and that modulates beta cell function. GIP acts on various tissues, including pancreatic beta cells, via interaction with its $G$ protein-coupled receptor. The most important effect of GIP is its potentiation of insulin secretion. In an earlier study, the authors took advantage 

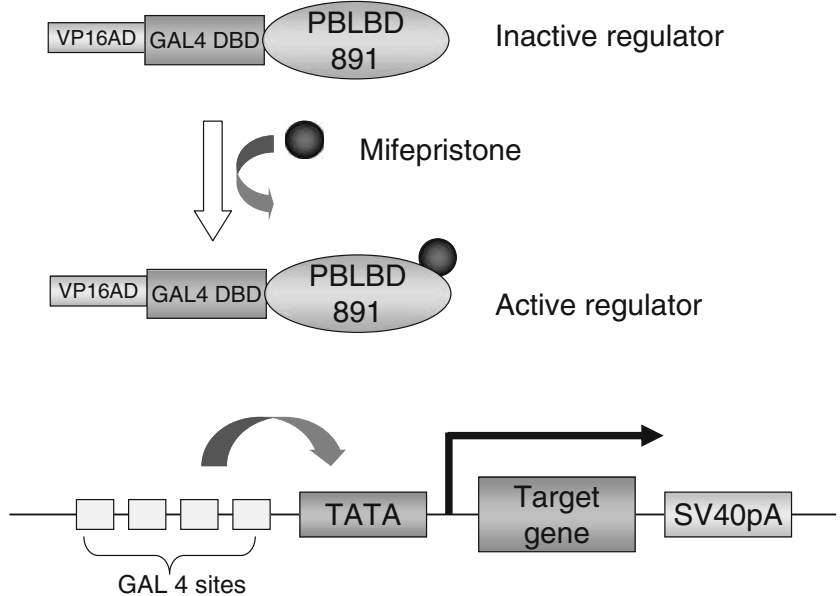

Fig. 1 The regulator is inactive in the absence of mifepristone. With mifepristone, the regulators are activated and undergo conformational change. The activated regulator then dimerizes and binds to the Gal4 DNA binding sites of the target gene, inducing target gene expression. Modified C-terminal ligand binding domain from the progesterone receptor (PR-891), mutant (PRLBD-891), Herpes simplex viral protein $(V P 16 A D)$, yeast transcription factor $(G a l 4 D B D)$, DNA sequence in the promoter region of a gene for regulation of transcription in eukaryotes (TATA-box)

of a tumor-derived $\mathrm{K}$ cell line, stenniocalcin-1 (STC-1) cells, that was induced to produce human insulin by providing the cells with the human insulin gene linked to the 5'-regulatory region of the gene encoding GIP. In that study, they found that mice expressing this transgene produced human insulin specifically in gut $\mathrm{K}$ cells. This insulin protected the mice from developing diabetes and maintained glucose tolerance after the destruction of the native insulin-producing beta cells [6].

STC-1 cells are derived from a mouse neuroendocrine tumor cell line. GTC-1 cells are a high GIP-expressing subpopulation of STC-1 cells. Two plasmids were used to establish insulin-producing GTC-1 cells. One plasmid contained a chimeric "gene-switch" protein that consisted of a progesterone receptor-ligand binding domain, a yeast GAL4 DNA binding domain, and a HSV transcriptional activation domain that was driven via a thymidine kinase promoter. The second inducible target plasmid contained the truncated human progesterone receptor construct (GAL4UAS) within the promoter and the genomic sequence of the human preproinsulin gene. GTC-1 cells were first transfected with the gene-switch protein plasmid and then stable clones were confronted with the second plasmid. Cells surviving this ordeal were then tested with mifepristone in terms of their insulin secretion. The authors then refined their cell lines and modified the gene-switch protein plasmid to replace the promiscuous tyrosine kinase promoter with promoter elements of nonsecretory cells. Thus, the resultant cells obeyed solely the mifepristone command in terms of insulin production. An appropriate mouse model (C57B6) was selected. Capsules containing the cells were delivered into the peritoneal cavity. Streptozotocin was given to kill all the endogenous islet cells in these mice.

The next question was: "How is mifepristone to be given?" Clinicians would have preferred a mifepristone dose with each meal. However, in this animal model, such an approach was not feasible. Mifepristone was implanted subcutaneously by means of a pellet. In short, the transplanted cells made insulin in response to mifepristone. Cpeptide and insulin production were demonstrated. In the mice, mifepristone administration dropped glucose levels from 23 to $5 \mathrm{mmol} / \mathrm{L}$; levels that clinicians have difficulty achieving in clinical practice. Diabetic mice with cells, but without mifepristone, remained at $25 \mathrm{mmol} / \mathrm{L}$ glucose values for the 20-day experiment. The authors then performed repetitive dosing experiments in diabetic and control mice. Glucose decreased from 25 to $<10 \mathrm{mmol} / \mathrm{L}$ on every day (days $7,11,15$, and 22 ) that mifepristone was given. Thus, the notion of giving the drug initiator on a daily basis was shown in these studies. Aside from the technical "tour-de-force," what can we take home from these studies?

As the authors showed in an earlier study, native K cells can be engineered to secrete insulin in quantities sufficient to replace insulin normally produced by islet beta cells. That system had problems with overproduction of insulin perhaps related to further cell growth or diminished glucose responsiveness of the $\mathrm{K}$ cells [6]. The regulated geneswitch could circumvent some of these problems. In any event, the authors claim that hypoglycemia was not a problem in this study. Nonetheless, are these data relevant to patients with diabetes? The authors admit that the current model is probably not very clinically relevant. First, the cells were derived from a tumor line. Thus, there are substantial safety issues that would need to be resolved. Second, the gene-switch provides its own clinical problems. Mifepristone is an abortifacient, but aside from that, progesterone antagonism brings with it another set of clinical problems. Current clinical therapy for T1DM relies on insulin pump placement.

The dream of an artificial beta cell is an old one. Christiansen et al. [7] tested the glucose analyzer and insulin infusion modules of the Biostator system almost 30 years ago. They found that the Biostator delivered $99 \%$ of the computed required insulin. Blood glucose results from the Biostator were compared with routine laboratory methods during long-term feedback control. The device enabled normal glucose tolerance to be achieved with smaller amounts of insulin. In a far more recent study, Shenkman et al. [8] reported on the "Development of an Implanted Biosensor for Continuous Care and Monitoring System of Diabetic Patients" study. Their reagentless device integrates a 
novel nanobiotechnological glucose-sensing array at the heart of a novel fluorimetric detector that relies on innovative hydrogel waveguide technology. Their ultimate goal is to devise a cybernetic, externally supervised "artificial pancreas." Finally, the beta cell transplant people appear to be making some progress as well. One approach might be packaging of functional insulin-producing cells in an immunoisolation device [9]. Thus, T1DM is approachable via various channels. Hopefully, the patients with this disease will soon have novel options from which to choose. The gene-switch idea is nice, "but it's mice."

Respectfully,

Friedrich C. Luft

\section{References}

1. Tufveson G (2009) An experience of pancreas and islet transplantation in patients with end stage renal failure due to diabetes type I. Curr Opin Organ Transpl 14:95-102

2. Mood ZA, Mehrabi A, Schmied BM, Müller SA, Engelmann G, Schemmer P, Weitz J, Büchler MW, Gebhard MM, Schmidt J
(2008) Review of various techniques of pancreas transplantation in rat model. J Surg Res 145:205-213

3. Unniappan S, Wideman RD, Donald C, Gunn V, Wall JL, Zhang Y-X, Webber TD, Cheung AT, Kieffer TJ (2009) Treatment of diabetes by transplantation of drug-inducible insulin-producing gut cells. J Mol Med doi:10.1007/s00109-009-0465-0

4. Wang Y, O'Malley BW Jr, Tsai SY, O'Malley BW (1994) A regulatory system for use in gene transfer. Proc Natl Acad Sci U S A 91:8180-8184

5. Chua SS, Wang Y, DeMayo FJ, O'Malley BW, Tsai SY (1998) A novel RU486 inducible system for the activation and repression of genes. Adv Drug Deliv Rev 30:23-31

6. Cheung AT, Dayanandan B, Lewis JT, Korbutt GS, Rajotte RV, Bryer-Ash M, Boylan MO, Wolfe MM, Kieffer TJ (2000) Glucosedependent insulin release from genetically engineered $\mathrm{K}$ cells. Science 290:1959-1962

7. Christiansen JS, Svendsen PA, Søegaard U, Frandsen M, Mathiesen E, Winther K, Deckert T (1981) An artificial betacell: assessment of the glucose analyser, infusion system and optimization of constants for the algorithms. Scand J Clin Lab Invest 41:647-654

8. Shenkman L, Koukaki M, Karamanou S, Economou A (2007) The P CEZANNE project: innovative approaches to continuous glucose monitoring. Conf Proc IEEE Eng Med Biol Soc 2007:6061-6064

9. Lee SH, Hao E, Savinov AY, Geron I, Strongin AY, Itkin-Ansari P (2009) Human beta-cell precursors mature into functional insulinproducing cells in an immunoisolation device: implications for diabetes cell therapies. Transplantation 87:983-991 